\title{
Os horizontes da percepção em Husserl e Merleau-Ponty
}

The horizons of perception in Husserl and Merleau-Ponty

SILVA, Denise Damaris; Mestre em Filosofia; UEMG

ddamaris@gmail.com

\section{Resumo}

Neste texto, apresentamos os pontos de vista de Husserl e Merleau-Ponty sobre os horizontes da percepção, explicitando a divergência central relacionada às noções de atenção, determinado/indeterminado e o conceito de normatividade, uma ampliação de Merleau-Ponty em relação à teoria de Husserl. A reflexão sobre os horizontes da percepção nos dois autores lança luz ao entendimento da percepção visual, com especial destaque para a questão figura/fundo no campo da Fenomenologia, ampliando as possibilidades de reflexão para os designers, para além da Gestalt.

Palavras Chave: percepção, figura-fundo, atenção.

\begin{abstract}
In this paper, we present the views of Husserl and Merleau-Ponty concerning the horizons of perception, and show their central difference, related to the notions of attention, to the determinate/indeterminate and to the concept of normativity, which is an enlargement proposed by Merleau-Ponty when compared to Husserl's theory. The study of the horizons of perception on both authors illuminates the topic of visual perception, specially the figure/bottom question in the Phenomenology sphere, and broaden the possibilities of reflexion by designers beyond Gestalt.
\end{abstract}

Keywords: Perception, figure-bottom, attention. 


\section{Introdução}

Como nos diz WACHOWICZ e ARBIGAUS (2003), a relação figura/fundo foi muito estudada pela Gestalt e é um dos meios de expressão gráfica fundamental para o trabalho do designer. Nas escolas de design, são recorrentes exercícios de percepção visual de figuras/fundo - como a da figura vaso/rosto - que explicitam a importância da observância desse princípio para a percepção visual e para sua aplicação no design.

Figura 1 - Vaso/Rosto

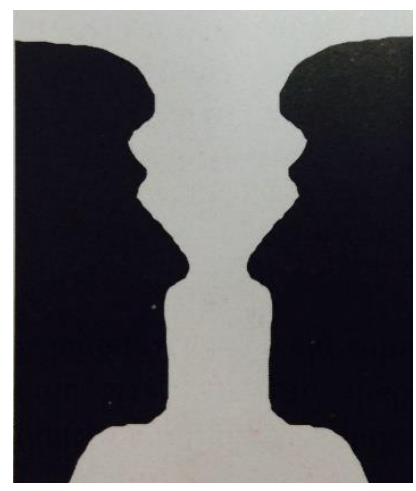

Fonte: Gestalt do Objeto (2000), p.90

A origem da Gestalt, ou Psicologia da forma, dá-se no mesmo contexto da Fenomenologia de Husserl, que, inclusive, dialoga com a Psicologia empírica do período em muitos dos seus escritos - ambas floresceram na Alemanha, no início do século XX.

O ensaio apresentado a seguir é uma reflexão filosófica sobre os horizontes da percepção em Husserl e Merleau-Ponty, que trava um diálogo com o primeiro. Os horizontes da percepção nos dois autores podem lançar luz ao entendimento da questão figura/fundo no campo da Fenomenologia, ampliando a reflexão para o designer, para além da Gestalt. Podem ampliar, também para o designer de produto, o entendimento da percepção visual dos objetos no espaço.

\section{Os horizontes da percepção em Husserl e Merleau-Ponty}

Ao observar certo objeto - um notebook, por exemplo - o vejo em determinada perspectiva. Se meu olhar se dirige à tela, apresenta-se a mim uma face diferente daquela que me seria apresentada caso eu estivesse olhando para a parte de trás do mesmo notebook. No entanto, vendo-o apenas por um perfil ou por outro, em mera perspectiva, ainda assim, eu possuo a experiência de um objeto completo. Essa experiência se dá de imediato, ao mesmo tempo em que ocorre o ato de perceber. Como pode ocorrer que, tendo apenas uma visão de fachada de objetos, posso experimentá-los como completos, em todas suas dimensões?

A questão dos horizontes da percepção, é muito importante para a fenomenologia da percepção, sendo central tanto para o pensamento de Husserl, o primeiro a formulá-la, quanto para o de Merleau-Ponty que a responde diferentemente daquele. 
Pretendemos expor os dois pontos de vista em relação à questão dos horizontes da percepção abordando as noções de determinado, indeterminado, abschattung ${ }^{\mathbf{1}}$, protensão, retenção, atenção, figura/fundo e normatividade.

\section{Husserl e as Abschattungen}

O atualmente percebido, o mais ou menos claramente percebido e determinado (ou ao menos razoavelmente determinado) é em parte impregnado, em parte envolto por um horizonte de realidade indeterminada, de que se tem obscuramente consciência. [...] $\mathrm{O}$ horizonte enevoado e jamais plenamente determinável está necessariamente aí. (HUSSERL, 2006, p. 74)

Nessa passagem, referindo-se à percepção, Husserl distingue entre o que é determinado, definido como o que nos é dado na percepção, podendo ter maior ou menor determinação e clareza, e o que é indeterminado.

\subsection{0 determinado}

Para Husserl, percebemos claramente aquilo para o que se volta nossa atenção. Ao digitar um texto no meu notebook, minha atenção está dirigida às palavras que surgem uma a uma. Menos claramente, percebo a página que é fundo para as palavras e as ferramentas do meu programa. Posso perceber ainda a moldura da tela e o teclado, a parede que está ao fundo, a estante que se ergue acima do computador e na escrivaninha no qual está apoiado, alguns livros e papeis. Tenho visão de tudo isso, com maior ou menor clareza, conforme se dirige minha atenção. Se ela se volta para um livro à minha esquerda, as palavras que digitei perdem clareza e ficam, juntamente com a tela do notebook e os objetos que estão à direita, numa espécie de penumbra perceptual. Todo esse cenário é, ainda assim, com maior ou menor clareza, percebido.

Sobre o poder de destaque da atenção sobre meu campo perceptivo, diferenciando entre o destacado (o determinado) e o restante do meu campo perceptivo (o mais ou menos determinado), diz Husserl:

No perceber propriamente dito, que é notar algo, estou voltado para o objeto, por exemplo, para o papel, eu o apreendo como este que é aqui e agora. O apreender é um destacar, todo percebido se dá sobre um fundo de experiência. Em torno ao papel estão os livros, canetas, tinteiros etc., de certo modo também "percebidos", perceptivamente ali, no "campo intuitivo", mas enquanto se está voltado para o papel, não há nenhuma apreensão,

${ }^{1}$ No centro da fenomenologia da percepção husserliana, encontra-se a descrição da coisa percebida com base na noção de Abschattung. (...). A etimologia do termo Abschattung refere-se à ideia da ação de uma sombra que pouco a pouco adquire contornos definidos. (...). Em português, conforme o uso corrente nos trabalhos e traduções consagrados a este domínio teórico, utilizaremos, preferencialmente, o termo "perfil" para nos referirmos à doação perceptiva por Abschattungen. Em Husserl, o termo remete “à emergência de um 'aparecendo' espacial no domínio originário da percepção" (English, 2002, p. 54, grifo do autor). O termo alude principalmente ao campo da percepção visual, ao fato de que aquilo que aparece "não pode jamais ser dado senão de um certo lado, em perspectiva, através de tais e tais contornos, sem que jamais sua face e seu avesso possam aparecer ao mesmo tempo" (English, 2002, p. 54, grifo do autor). (VERÍSSIMO. D. S. V. A teoria husserliana da doação perceptiva por perfis. in: Psicologia. São Paulo: USP. Vol.27, n.3, p.522). Optamos pela permanência do termo Abschattung em algumas partes do texto para enfatizar a terminologia husserliana, já que se trata de um conceito muito forte nos textos de Husserl sobre a percepção. Nas demais partes, utilizamos o termo em português "perfil", conforme indicado acima. 
mesmo secundária, voltada para eles. Eles apareciam e, não obstante, não eram realçados, postos por si. Toda percepção de coisa tem, assim, um halo de intuição de fundo (ou de visões de fundo, caso já se compreenda no intuir o "estar-voltado-para") e este também é um vivido de consciência "de" tudo aquilo que está de fato contido no "fundo" objetivo cointuído. (HUSSERL, 2006, p. 87)

Nessa passagem, Husserl diferencia, em relação ao que está no campo perceptual, entre o que é destacado pela atenção e o que não é. É importante notar que ele toma o termo percepção de dois modos: um, mais robusto, como no trecho "no perceber propriamente dito, que é notar algo, estou voltado para o objeto. (...)". Aqui, ele se refere ao perceber estrito como o voltar-se para o objeto, ou seja, dirigir a atenção para determinado objeto. Já no trecho "Em torno ao papel estão os livros, canetas, tinteiros, etc., de certo modo também 'percebidos' (...)'" ele amplia o escopo da percepção também para o que não é destacado pela atenção, para o meio circundante, que está no campo perceptivo como "co-intuído". Apesar de apresentarem-se à experiência de modos diferentes ("de certo modo" e "propriamente dito"), são ambos percebidos: os objetos para os quais se voltam a atenção e os que aparecem como fundo por não serem foco da atenção. E se são ambos percebidos, de acordo com a própria noção husserliana do determinado, podemos afirmar que são para Husserl, tanto a figura como o fundo, determinados.

\subsection{0 indeterminado}

Mas além do que é percebido, seja com maior ou menor clareza e determinação, ainda se apresenta a mim, de alguma forma, uma realidade indeterminada que permite com que eu experimente coisas além de meras fachadas; verdadeiros objetos que transcendem aquilo que deles percebemos.

Assim ocorre com a parte traseira do meu notebook, a qual não viso. Essa face oculta não se apresenta à minha percepção atual, mas está, de alguma maneira, presente na experiência desse objeto. De alguma forma, eu sei que ela está presente, eu sei que ela está ali. Ela faz parte de um horizonte indeterminado que impregna minha percepção atual e faz parte dessa experiência, mas não como uma percepção, pois não se determina pela percepção. As faces ocultas dos objetos, indeterminadas, são hipóteses, horizontes possíveis à minha percepção e, se possíveis e hipotéticas são, portanto, não presentes, são ausentes na percepção.

\subsection{Abschattungen}

O mundo nos é apresentado em perfis, sempre defasados em relação ao objeto transcendente $^{2}$. Como não posso perceber o objeto em sua totalidade, mas apenas perfilado, esses perfis ou Abschattungen constituem percepções inadequadas ou não completas desse objeto, mais ou menos determinadas de acordo com o direcionamento da minha atenção. Quando observo um objeto, há sempre uma parte que não me é mostrada, uma face oculta. Isso, no entanto, não me impede de ter a identidade da coisa. A face oculta do objeto me é apresentada de certa maneira,

${ }^{2}$ Objeto transcendente é, para Husserl, aquele que, em orientação natural, chamamos coisa objetiva. Husserl realiza uma espécie de inversão do conceito anterior de transcendentalidade que tomava por transcendente o que Husserl considera como imanente. Objeto transcendente se refere à res extense; é, pois, aquele que não podemos perceber por completo, justamente por ser dado necessariamente perfilado. Não podemos, contudo, confundir o transcendente com o transcendental, que adquire um novo sentido na fenomenologia husserliana. 
vivenciado mesmo quando não surge à minha percepção. Mas, para Husserl, não é porque esse perfil oculto é vivenciado que ele é percebido. Ele me é dado como horizonte ou possibilidade de uma percepção que não se dá, que não se completa. Assim, quando vejo a tela do meu notebook, sua parte traseira não se dá na percepção, já que no momento em que miro a tela não acesso esse perfil escondido.

Essas apresentações por Abschattungen, inadequadas, são marcas descritivas de objetos transcendentes. Não há possibilidade de que haja percepção adequada; é necessário que a percepção transcendente ${ }^{3}$ se dê dessa maneira inadequada, perfilada que é, inclusive, a forma de reconhecermos um objeto como transcendente. Diz Husserl:

\begin{abstract}
Da percepção de coisa faz parte, além disso, e também por necessidade de essência, certa inadequação. Uma coisa, por princípio, só pode ser dada "por um dos seus lados", e isso não significa apenas de maneira incompleta, imperfeita, num sentido qualquer, mas significa justamente o que é prescrito pela exibição por perfil. Uma coisa é dada necessariamente em meros "modos de aparição", neles um núcleo do "efetivamente exibido" é necessariamente envolto, no que se refere à apreensão, por um horizonte de "dados concomitantes" inautênticos e por uma indeterminidade mais ou menos vaga. E o sentido dessa indeterminidade é mais uma vez prescrito pelo sentido geral do percebido propriamete dito e como tal, por exemplo, pela essência geral desse tipo de percepção que chamamos percepção da coisa. (HUSSERL, 2006, p. 104)
\end{abstract}

Nessa passagem Husserl deixa claro seu ponto de vista: é por essência que a percepção transcendente seja dada em meros perfis, permanecendo sempre um horizonte com multiplicidades de percepções possíveis.

A experiência da face oculta, como indeterminada, não pode ser dada na percepção.

\title{
3.4 A imaginação, a protensão e a retenção
}

A imaginação e não a percepção que é, para Husserl, o ato responsável pela experiência de totalidade que temos na percepção transcendente. Somente a imaginação pode variar a vivência atual e revelar as possibilidades ou o horizonte que excede o apreendido no universo da empiria.

Diz Husserl: "A percepção da coisa não presentifica um não-presente, como se fosse uma recordação ou uma imaginação; ela apresenta, ela apreende um algo ele mesmo em sua presença em carne e osso." (HUSSERL, 2006, p. 103)

${ }^{3}$ Husserl utiliza o termo Percepção Transcendente oposto ao termo Percepção Imanente. Referindo-se a Brentano e à tradição filosófica que já fazia a distinção entre "percepção interna" e "percepção externa", Husserl atualiza o conceito não mais identificando o imanente ao "interno" e o transcendente ao "externo". Husserl toma por percepção imanente aquela que ocorre quando os objetos intencionais fazem parte do mesmo fluxo de vividos que o próprio cogito ou ato da consciência. Já com relação à percepção transcendente, não há essa unidade entre cogito e objeto intencional. Pelo contrário, há uma separação que ocorre apenas nesse tipo de percepção. Husserl recoloca a problemática, dessa maneira, em termos de união e separação entre cogito e objeto intencional, escapando de situações fenomenológicas complexas se pensadas em termos de interno e externo, como as dores e sensações do próprio corpo. Diz Husserl no §38 Ideias para uma fenomenologia pura e uma filosofia fenomenológica: "em sua composição real, a percepção da coisa não só não contém em si a própria coisa, mas também está fora de toda unidade essencial com ela, pressupondo-se naturalmente, que esta exista." A percepção a qual nos referimos no texto é a percepção transcendente, que diz respeito ao objeto transcendental, e, portanto, separado do próprio ato da consciência. 
Husserl realiza, nessa passagem, justamente uma contraposição entre os atos de perceber e de recordar e imaginar. Perceber é apreender o próprio presente dado aos sentidos; a imaginação e recordação dizem respeito ao que não está presente na minha esfera de percepção, portanto, também a essas faces que não aparecem no agora. Realizo antecipações (protensões) e recordações (retenções) para experimentar um objeto em totalidade e num fluxo temporal. A protensão seria o futuro contido no presente, ou a capacidade de antecipar o que virá como forma presentificada. A retenção ocorre quando o passado é trazido para a experiência do agora, de forma a experimentarmos a percepção não como pontual, mas sim como temporal.

Sobre os horizontes da percepção transcendente, delineados pela protensão e retenção, diz Husserl:

\begin{abstract}
Assim, por exemplo, em toda percepção exterior, os lados do objeto que são "realmente percebidos" remetem aos que ainda não o são e que somente são antecipados na expectativa de maneira não intuitiva como aspectos "que estão por vir" na percepção. Esta é uma "protensão" contínua, que, para cada nova fase perceptiva, assume um novo sentido. [...] Além disso - e vamos aqui preencher uma lacuna -, a toda percepção pertence sempre um espectro de percepções passadas, que se deve conceber como potencialidades de lembranças susceptíveis de serem recordadas, e a toda lembrança em si pertence, como "espectro", a intencionalidade mediata e contínua de lembranças possíveis (realizadas por minha atividade), até chegar ao instante da minha percepção atual. (HUSSERL, 2001, p. 62)
\end{abstract}

\title{
4. Merleau-Ponty e a percepção do indeterminado
}

Merleau-Ponty concorda com Husserl que não possuímos dados dos sentidos de um objeto completo e também que a experiência de um objeto pode ser determinada ou indeterminada. Mas discorda sobre o que seria o determinado e o indeterminado e, de acordo com sua definição, formula que as características indeterminadas possuem presença positiva na experiência.

O determinado seria, portanto, a percepção em que certa face me é mostrada diretamente, focalmente, como figura; o indeterminado, que Husserl define como o não dado pela percepção, é, para Merleau-Ponty, uma percepção; uma visão de je ne sais quoi (de não sei o quê), uma visão do indeterminado. Sendo assim, A experiência do indeterminado existe como percepção. Ou seja, eu percebo a face oculta, a experimento não como um horizonte ou uma possibilidade, mas como percepção, como fundo para minha figura. Há, ao contrário de Husserl, presença perceptual.

\subsection{Crítica à noção de atenção}

Podemos compreender melhor as noções de determinado e indeterminado de MerleauPonty através da sua crítica à noção de atenção que, para ele, se mostra incapaz de lidar com a questão da diferença entre figura e fundo. Critica o filósofo:

Poder-se-ia mostrá-lo estudando a história do conceito de atenção. Ele se deduz, para o empirismo, da "hipótese de constância", quer dizer, como nós o explicamos, da prioridade do mundo objetivo. Mesmo se aquilo que percebemos não corresponde às propriedades objetivas do estímulo, a hipótese de constância obriga a admitir que as "sensações normais" já estão ali. É preciso então que elas estejam despercebidas, e chamar-se-á de atenção a função que as revela, assim como um projetor ilumina objetos preexistentes na sombra. 0 ato de atenção então não cria nada, e é um milagre natural, como dizia mais ou menos 
Malebranche, que faz jorrar justamente as percepções ou as idéias capazes de responder às questões que eu me colocava. (MERLEAU-PONTY, 1999, p. 53-54)

No trecho acima, Merleau-Ponty discorre sobre a atenção, ironizando-a ao chamá-la de "milagre natural", com a acusação de ser um conceito criado artificialmente apenas para responder às dificuldades surgidas. Para Merleau-Ponty, a atenção encobre as diferentes experiências que tenho da figura e do fundo ao colocar ambas no mesmo plano, sendo apenas discerníveis secundariamente por esse ato "misterioso".

Husserl já havia apresentado a dificuldade em diferenciar as experiências de percepção da figura e do fundo nos termos dos seus conceitos de determinado e indeterminado. Ele apontou a questão ao formular diferentes modos de lidar com o termo percepção: um, referente aqueles objetos para os quais se voltam minha atenção e outro, aqueles que estão no meu campo perceptual, mas apenas como meio circundante, sem destaque, em outras palavras, à figura e ao fundo. No entanto, mesmo diferenciando as maneiras de perceber figura e fundo, Husserl considera ambas determinadas. $O$ indeterminado seria apenas o que não está de forma alguma no campo perceptivo, como as faces ocultas, que são apresentadas na experiência apenas como possibilidades ou horizontes da percepção.

Merleau-Ponty se coloca contrário a essa posição ao defender que o que surge como fundo é, juntamente com as faces ocultas, também indeterminado e essa é a forma de diferenciar entre a figura que está no foco (determinada) e o meio circundante (indeterminado). Somente dessa forma, para Merleau-Ponty, podemos descrever as diferentes experiências que temos na percepção da figura e do fundo.

\subsection{Normatividade}

O fundo, para Merleau-Ponty, confere normatividade à percepção. Observemos, por exemplo, uma folha de papel com um texto sob uma iluminação fraca, na penumbra. Após a primeira observação, regulamos a luz de forma que possamos ler o texto confortavelmente. A luz, indiscutivelmente, torna a percepção dos objetos que varre mais ou menos nítida; contudo, parece estranho pensar que a luz, por si só, revela dados aos sentidos. Segundo Merleau-Ponty, Husserl teria que assumir justamente isso: que a luz, por si, possui presença perceptual, mesmo que menos claramente. Isso porque revela dados aos sentidos, estando presente no campo perceptivo. Seria, dessa forma, determinada.

Para Merleau-Ponty, essa não é a forma correta de se analisar a situação apresentada. É muito estranho tomar a luz com presença perceptual determinada, no mesmo sentido que a folha de papel. Eu não experimento a folha de papel da mesma forma que experimento a luz. A luz é fundo para a experiência do papel e possui caráter normativo em relação a essa experiência. Possui caráter normativo porque na minha experiência do papel já está contido o desejo de ler o texto e de alterar a luz para que a leitura seja agradável. Há uma luminosidade ideal que serve de norma para minha leitura do texto e essa luminosidade é aquela a qual viso. A segunda situação, no qual a leitura se dá, é, obviamente, mais adequada à minha experiência com o objeto. 
Figura 1 - Le bassin aux nymphéas, harmonie verte - Monet

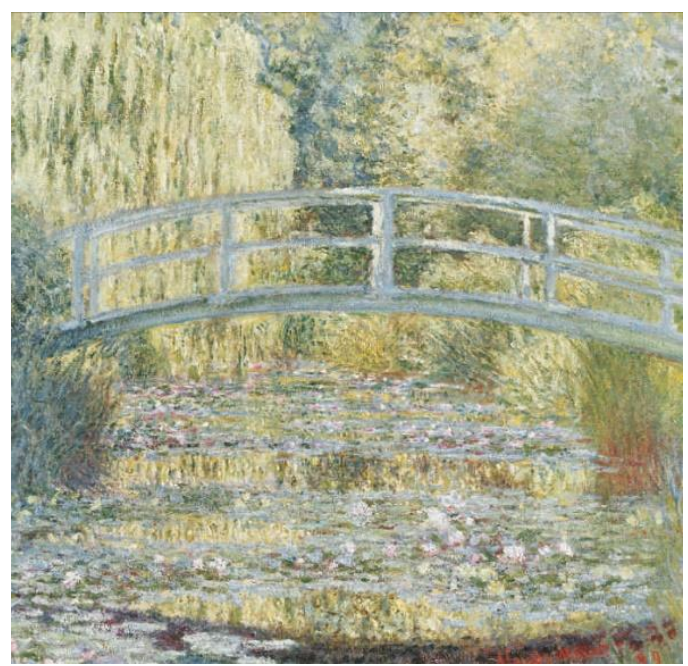

Fonte: Impressionismo: Paris e modernidade (2012)

Um exemplo de como a dimensão normativa é essencial para nossa experiência perceptual é a observação de um quadro impressionista. A pintura impressionista, o quadro Le bassin aux nymphéas, harmonie verte, de Monet, por exemplo, pede, de certa maneira, determinada distância para a uma observação adequada. A adequação se dá entre a atual experiência perceptual e a melhor experiência perceptual possível. Dessa maneira, se, inicialmente, me posiciono a poucos centímetros desse quadro, sinto rapidamente um impulso que me leva a distanciar-me da obra, até certo ponto, o qual considero ideal para sua apreciação.

De maneira análoga à iluminação ideal para a leitura do texto, ocorre com as apresentações do objeto, sempre em perspectiva. Nesse caso, não há, empiricamente, uma apresentação ideal, visto que todas são dadas em meros perfis, que são incompletos e em perspectiva. Contudo, há perspectivas mais próximas ao ideal que outras, na medida em que revelam mais o objeto do que aquelas. Assim, ao avistar uma caneca, por exemplo, a perspectiva que mais me aproxima do objeto é aquela em que viso a alça e não aquela em que só é me mostrada a superfície cilíndrica. Mas aquele perfil, apesar de se apresentar como o mais adequado possível, ainda se determina a partir de uma percepção que é completa e, visto que essa completude é por si uma impossibilidade empírica, é, por isso, ideal.

Dessa maneira, a visão ideal, inacessível empiricamente, seria a visão do objeto completo. Para Merleau-Ponty é, então, a soma das perspectivas à experiência ideal, que normatiza a minha experiência perceptual: “O objeto acabado é translúcido, ele está penetrado de todos os lados por uma infinidade atual de olhares que se entrecruzam em sua profundeza e não deixam nada escondido." (MERLEAU-PONTY, 1999, p. 106)

O "objeto completo", a norma para minha visão em perspectiva, é essa soma de visões. Essa soma, mesmo sendo irrealizável, é a norma para minha experiência. E é essa a característica mais básica da percepção: a normatividade e não, como para Husserl, a apresentação de dados aos sentidos.

Podemos notar que na experiência figura/fundo, o fundo possui função normativa na medida em que fornece outras perspectivas possíveis, ou horizontes de visada do meu objeto, 
apresentando a mim a perspectiva melhor que eu poderia ter dele. Esses horizontes, além de conferirem a norma para minha percepção, criam também a identidade do objeto, visto que ele se verifica através do horizonte, através de cada visada possível. É como se as coisas se mostrassem umas às outras, como espelhos:

\begin{abstract}
Ver é entrar em um universo de seres que se mostram, e eles não se mostrariam se não pudessem estar escondidos uns atrás dos outros ou atrás de mim. Em outros termos: olhar um objeto é vir habitá-lo e dali apreender todas as coisas segundo a face que elas voltam para ele. Mas, na medida em que também as vejo, elas permanecem moradas abertas ao meu olhar e, situado virtualmente nelas, percebo sob diferentes ângulos o objeto central de minha visão atual. Assim, cada objeto é o espelho de todos os outros. Quando olho o abajur posto em minha mesa, eu the atribuo não apenas as qualidades visíveis a partir de meu lugar, mas ainda aquelas que a lareira, as paredes, a mesa podem "ver", o verso de meu abajur é apenas a face que ele "mostra" à lareira. Portanto, posso ver um objeto enquanto os objetos formam um sistema ou um mundo e enquanto cada um deles dispõe dos outros em torno de si como espectadores de seus aspectos escondidos e garantia de sua permanência. (MERLEAU-PONTY, 1999, p. 105)
\end{abstract}

Para Merleau-Ponty, ao percebermos coisas, não estamos voltados apenas para o que percebemos como dados dos sentidos, mas também para o modo como percebemos e o melhor modo de percebermos aquilo que desejamos perceber. Para ele, percebemos então como devemos nos mover e nos posicionar para potencializarmos nossa percepção.

Dessa maneira, diferentemente de Husserl, Merleau-Ponty afirma que percebemos o indeterminado, que não é somente o fundo já apresentado aos sentidos e ausente enquanto foco. Percebo também as faces ocultas, embora indeterminadamente, já que posso habitar o objeto e experimentar os horizontes da percepção como forma de adequar a minha experiência. Esse fundo normativo é o que confere sentido à minha experiência, assim como move minha ação que intenciona a melhor percepção.

\title{
4.3 Voltando a Husserl
}

Se, para Merleau-Ponty as faces ocultas são apreendidas pela percepção, para Husserl, como dito anteriormente, não podemos falar de percepção das faces ocultas já que a percepção é a apreensão em "carne e osso" e as faces ocultas não são dadas aos sentidos. A percepção é, por essência, unilateral e inadequada. Há, contudo, a apreensão completa da coisa, de forma que em meio à multiplicidade infinita de aparições, forma-se uma unidade de sentido, unificadora dessa multiplicidade. As coisas são de fato apreendidas como unidades, apesar da inadequação da percepção, como ele afirma nessa passagem:

Retenhamos, pois, isso: se, por um lado, é da essência do dado por aparições que nenhuma delas dê a coisa como um 'absoluto', e não em exibição parcial, por outros, é da essência do dado imanente dar justamente um absoluto, que não pode de modo algum se exibir ou perfilar por seus lados" (HUSSERL, 2006, p. 105).

Algo nos dá a apreensão completa da coisa, para além da sua percepção, sempre inadequada. Mas isso é assunto para um outro texto ou vários outros. 


\section{Referências Bibliográficas}

HUSSERL, E. Ideias para uma fenomenologia pura e para uma filosofia fenomenológica: introdução geral à fenomenologia pura. Trad. Márcio Suzuki. São Paulo: Idéias e Letras, 2006.

Paulo: Mandras, 2001.

Meditações Cartesianas - introdução à fenomenologia. Trad. Frank de Oliveira. São

PONTY, M. M. The Phenomenology of Perception. Trad. Colin Smith. Ed.Taylor and Francis $e-$ Library, 2005.

, M. M. Fenomenologia da percepção. Trad. Carlos Alberto Ribeiro de Moura. São Paulo: Martins Fontes, 1999.

M. M. O primado da percepção e suas consequências filosóficas. Trad.: Constança Marcondes Cesar. Campinas: Papirus, 1990.

HUSSERL, E; MERLEAU-PONTY, M; Textos escolhidos. Investigações lógicas: sexta investigação: elementos de uma elucidação fenomenológica do conhecimento. São Paulo: Victor, Civita, 1975.

DEPRAZ, N. Compreender Husserl. Trad. Fábio dos Santos. Petrópolis: Vozes, 2011.

SMITH, B., SMITH, D. (Orgs). The Cambridge companion to Husserl. New York: Cambridge University Press, 1995.

KELLY, S. D. "Seeing things in Merleau-Ponty". Cambridge companion to Merleau-Ponty. Ed. Taylor Carman and Mark Hansen. Cambridge: Cambridge University Press, 2005.

WACHOWICZ, L. A. e ARBIGAUS, M. L. G. Aprendizagem por meio da Gestalt na formação de competências do profissional de Desenho Industrial. In: Revista Diálogo Educacional, Curitiba, v. 4, n. 9, pp. 91-104, maio/ago. 2003.

VERÍSSIMO. D. S. V. A teoria husserliana da doação perceptiva por perfis. in: Psicologia. São Paulo: USP. v. 27.

GOMES FILHO, J. Gestalt do objeto: sistema de leitura visual da forma. 6. Ed. São Paulo: escrituras, 2004.

CCBB EDUCATIVO. Impressionismo: Paris e modernidade. São Paulo, 2012. 